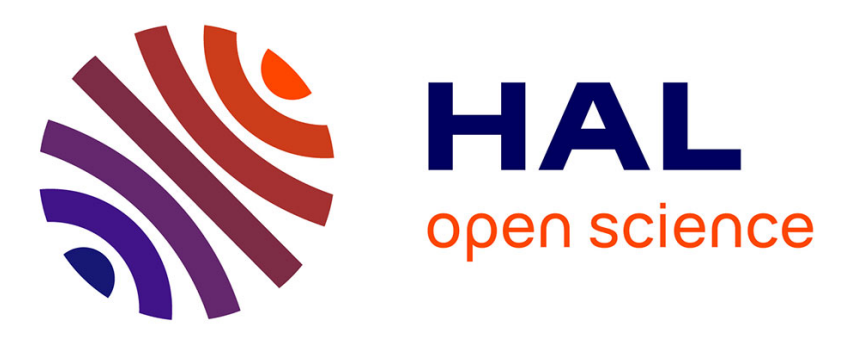

\title{
14N Nuclear Quadrupole Coupling and Methyl Internal Rotation in N-tert-Butylacetamide As Observed by Microwave Spectroscopy
}

Raphaela Kannengiesser, Wolfgang Stahl, Ha Vinh Lam Nguyen, Isabelle Kleiner

\section{To cite this version:}

Raphaela Kannengiesser, Wolfgang Stahl, Ha Vinh Lam Nguyen, Isabelle Kleiner. $14 \mathrm{~N} \mathrm{Nu-}$ clear Quadrupole Coupling and Methyl Internal Rotation in N-tert-Butylacetamide As Observed by Microwave Spectroscopy. Journal of Physical Chemistry A, 2016, 120 (23), pp.3992-3997. 10.1021/acs.jpca.6b02111 . hal-03183142

\section{HAL Id: hal-03183142 \\ https://hal.science/hal-03183142}

Submitted on 26 Mar 2021

HAL is a multi-disciplinary open access archive for the deposit and dissemination of scientific research documents, whether they are published or not. The documents may come from teaching and research institutions in France or abroad, or from public or private research centers.
L'archive ouverte pluridisciplinaire HAL, est destinée au dépôt et à la diffusion de documents scientifiques de niveau recherche, publiés ou non, émanant des établissements d'enseignement et de recherche français ou étrangers, des laboratoires publics ou privés. 


\title{
${ }^{14} \mathrm{~N}$ Nuclear Quadrupole Coupling and Methyl
}

\section{Internal Rotation in N-tert-butylacetamide as}

\section{Observed by Microwave Spectroscopy}

\author{
Raphaela Kannengießer ${ }^{a}$, Wolfgang Stahl ${ }^{a}$, Ha Vinh Lam Nguyen ${ }^{b, *}$, and Isabelle Kleiner ${ }^{b}$ \\ ${ }^{a}$ Institute of Physical Chemistry, RWTH Aachen University, Landoltweg 2, D-52074 Aachen, \\ Germany \\ b Laboratoire Interuniversitaire des Systèmes Atmosphériques (LISA), CNRS UMR 7583, \\ Université Paris-Est Créteil, Université Paris Diderot, 61 avenue du Général de Gaulle, F-94010 \\ Créteil cedex, France
}

\begin{abstract}
The rotational spectrum of N-tert-butylacetamide, $\mathrm{CH}_{3}(\mathrm{C}=\mathrm{O})(\mathrm{NH}) \mathrm{C}\left(\mathrm{CH}_{3}\right)_{3}$, was measured in the frequency range from 2 to $26.5 \mathrm{GHz}$ using a molecular beam Fourier transform microwave spectrometer. Only one conformer with trans configuration and $\mathrm{C}_{\mathrm{s}}$ symmetry was observed. Torsional splittings up to $4.3 \mathrm{GHz}$ occurred in the spectrum due to the internal rotation of the acetyl methyl group $\mathbf{C H}_{3}(\mathrm{C}=\mathrm{O})$ with a barrier height of approximately $65 \mathrm{~cm}^{-1}$. Hyperfine structures arise from the quadrupole coupling of the ${ }^{14} \mathrm{~N}$ nucleus appeared for all rotationaltorsional transitions. The data set was reproduced with the programs $X I A M$ and $B E L G I-C_{l^{-}}$
\end{abstract}


hyperfine, an extended version of the BELGI-Cl code which includes the effect of the ${ }^{14} \mathrm{~N}$ quadrupole coupling, to root-mean-square deviations of $16.9 \mathrm{kHz}$ and $3.0 \mathrm{kHz}$, respectively. Quantum chemical calculations were performed to complement the experimental results. The BELGI-Cl-hyperfine code was also used to refit the recently published microwave data of Nethylacetamide to measurement accuracy.

KEYWORDS: rotational spectroscopy, large amplitude motion, acetyl methyl group, $B E L G I-C_{1}$

\section{INTRODUCTION}

The microwave spectrum of a molecule possessing internal rotation of a methyl group exhibits torsional splittings of all rotational lines into large amplitude motion (LAM) symmetry species components, and can no longer be treated using a rigid-rotor model. Several programs have been developed to treat this problem, i.a. IAM,${ }^{1}$ XIAM,${ }^{2}$ BELGI- $C_{s}{ }^{3}$ and BELGI-C $C_{l},{ }^{4}$ Erham,${ }^{5}$ and RAM36. ${ }^{6}$ They use different coordinate systems, e.g. the XIAM code uses the combined axis method; Erham sets up and solves an Effective Rotational HAMitonian; and BELGI-C, BELGI$C_{1}$, as well as $R A M 36$ use the rho axis method.

If the molecule has, in addition to the methyl top, a nucleus with a nuclear spin larger than $1 / 2$ (for example a ${ }^{14} \mathrm{~N}$ nucleus with $I=1$ ), a hyperfine structure (hfs) will occur in the spectrum. The combination of ${ }^{14} \mathrm{~N}$ quadrupole coupling and methyl internal rotation can be handled with the program $R A M 36$, but only for molecules with $\mathrm{C}_{\mathrm{s}}$ symmetry. ${ }^{7}$ Using the program XIAM, the frame symmetry is not restricted to $\mathrm{C}_{\text {s. }}$ XIAM treats nuclear quadrupole interactions with one coupling nucleus in a first order approximation, which is sufficient to fit the hyperfine structure of nuclei with relatively small quadrupole moments like ${ }^{14} \mathrm{~N}$. However, the program XIAM has its disadvantages at treating internal rotations with low barrier heights, since only a limited number 
of parameters can be fitted and also since the torsional interactions between different $\mathrm{v}_{\mathrm{t}}$ states are not taken into account explicitly. Higher order terms cannot be easily implemented in the program.

N-tert-butylacetamide (TBAA), $\mathrm{CH}_{3}(\mathrm{C}=\mathrm{O})(\mathrm{NH}) \mathrm{C}\left(\mathrm{CH}_{3}\right)_{3}$, with the structure depicted in Figure 1 is the typical example of a molecule with one methyl internal rotation and ${ }^{14} \mathrm{~N}$ quadrupole coupling. TBAA has an amide bond, which connects the acetyl methyl group $\mathbf{C H}_{3}(\mathrm{C}=\mathrm{O})$ and the tert-butyl group. We expect the spectrum of TBAA to be that of a simple acetyl-methyl-top molecule since: (i) the tert-butyl rotor has a moment of inertia about 20 times larger than that of a methyl group, and (ii) splittings arising from internal rotations of the three methyl groups within the tert-butyl moiety should be quite small, since the barrier heights are expected to be approximately $1000 \mathrm{~cm}^{-1}$, close to that of the methyl group in ethyl fluoride. ${ }^{8}$

Chemically, TBAA belongs to the class of acetamides; it is used as a biochemical for proteomics research. Many acetamides have been the object of our microwave studies, i.a. N-ethylacetamide (EAA), $\mathrm{CH}_{3}(\mathrm{C}=\mathrm{O})(\mathrm{NH}) \mathrm{CH}_{2} \mathrm{CH}_{3},{ }^{9}$ and $\mathrm{N}, \mathrm{N}$-diethylacetamide, $\mathrm{CH}_{3}(\mathrm{C}=\mathrm{O}) \mathrm{N}\left(\mathrm{CH}_{2} \mathrm{CH}_{3}\right)_{2},{ }^{10}$ aiming to determine conformational and dynamical properties of structural motif within larger biological systems like entacapon, LSD (D-lysergic acid diethylamide), and melatonins. In our recent investigation on EAA, ${ }^{9}$ we observed only one conformer with $\mathrm{C}_{1}$ symmetry under molecular jet conditions. The microwave spectrum with $150 \mathrm{~A}$ and $121 \mathrm{E}$ species torsional and hfs components was fitted using the program XIAM to a standard deviation of $9.8 \mathrm{kHz}$. Attempts to reduce the standard deviation to measurement accuracy of $2 \mathrm{kHz}$ failed. We thus concluded that some higher order terms required to fit the spectrum of EAA were missing in the XIAM code, similar to the situation found in some other molecules where the barrier to internal rotation is comparably low $\left(73.4782(1) \mathrm{cm}^{-1}\right)$. Since the barrier height of the acetyl methyl group in TBAA 
is expected to be close to that found in EAA, the same problem might occur by fitting the spectrum of TBAA using the program XIAM.

In many previous investigations, we succeeded to fit the microwave spectra of molecules with $\mathrm{C}_{\mathrm{s}}$ symmetry and one methyl top with low barrier height to experimental accuracy using the program $B E L G I-C_{s}$, e.g. ethyl acetate, ${ }^{11}$ vinyl acetate, ${ }^{12}$ and methyl neopentyl ketone. ${ }^{13}$ The program BELGI in the $\mathrm{C}_{1}$ version also shows its efficiency for molecules like allyl acetate, ${ }^{14}$ linalool, ${ }^{15}$ isoamylacetate, ${ }^{16}$ allyl ketone, ${ }^{17}$ butyl acetate, ${ }^{18}$ pentyl acetate, ${ }^{19}$ and hexyl acetate. ${ }^{20}$ However, both $B E L G I-C_{s}$ and $B E L G I-C_{1}$ do not include the effect of quadrupole coupling.

We therefore decided to modify the BELGI-C $C_{l}$ code to BELGI-C $C_{1}$-hyperfine by including weak nuclear quadrupole coupling using a first order perturbation approximation. We used this modified version to refit the data set of EAA given in Ref. 9. Since the program $B E L G I-C_{l}$ is an extended version of the program $B E L G I-C_{s}$, it is possible to use the BELGI-C -hyperfine code to fit the spectra of molecules with $\mathrm{C}_{\text {s }}$ symmetry by setting all the out-of-plane terms to zero. As we shall see below, this program was also successfully applied to TBAA, exhibiting $\mathrm{C}_{\text {s }}$ symmetry. The remainder of this paper is divided into sections dealing with: the results of quantum chemical calculations and a short presentation of the theoretical model, experimental details, assignments and fits of the spectral data, and a brief discussion of our results.

\section{THEORETICAL}

Quantum chemical calculations. All calculations were carried out at the MP2/6-311++G(d,p) level of theory using the program GAUSSIAN $09 .{ }^{21}$

Conformational analysis. In TBAA, the rotation about the $\mathrm{C}_{3}-\mathrm{C}_{5}$ bond (for atom numbering see Figure 1) by varying the dihedral angle $\gamma=\angle\left(\mathrm{O}_{4}-\mathrm{C}_{3}-\mathrm{C}_{5}-\mathrm{H}\right)$ corresponds to the internal rotation of 
the acetyl methyl group. The rotations about the $\mathrm{C}_{9}-\mathrm{C}_{10}, \mathrm{C}_{9}-\mathrm{C}_{14}$, and $\mathrm{C}_{9}-\mathrm{C}_{18}$ bonds correspond to internal rotations of the three tert-butyl methyl groups. The rotation about the $\mathrm{C}_{3}-\mathrm{N}_{1}$ bond by varying the dihedral angle $\theta=\angle\left(\mathrm{O}_{4}-\mathrm{C}_{3}-\mathrm{N}_{1}-\mathrm{C}_{9}\right)$ creates trans and cis amides. A stable cis and a stable trans conformation were found, which will be called the cis conformer and the trans conformer throughout this paper. The cis conformer was predicted to have the rotational constants $A=3159.3 \mathrm{MHz}, B=1362.5 \mathrm{MHz}$, and $C=1216.1 \mathrm{MHz}$, as well as the dipole moment components $\mu_{a}=4.19 \mathrm{D}, \mu_{b}=2.18 \mathrm{D}$, and $\mu_{c}=0.11 \mathrm{D}$. The trans conformer, shown in Figure 1, has $\mathrm{C}_{\mathrm{s}}$ symmetry. Its predicted rotational constants are $A=3307.1 \mathrm{MHz}, B=1365.5$ $\mathrm{MHz}$, and $C=1237.8 \mathrm{MHz}$, and the calculated dipole moment components are $\mu_{a}=1.04 \mathrm{D}, \mu_{b}=$ 3.81 D, and $\mu_{c}=0.00 \mathrm{D}$. The Cartesian coordinates of both conformers are given in Table S-1 in the supporting information (SI). It should be noted that the trans conformer is $21.15 \mathrm{~kJ} \cdot \mathrm{mol}^{-1}$ lower in energy than the cis conformer. Therefore, we do not expect to observe the cis conformer in our spectrum under molecular jet conditions, and only focus on the trans conformer in this paper.

${ }^{14} \mathrm{~N}$ nuclear quadrupole coupling constants. From the optimized structure of the trans conformer, a single point calculation of the electric field gradient was carried out at the B3PW91/6-311+(df,pd) level of theory using a calibration factor of $\mathrm{eQ} / \mathrm{h}=4.5586(40) \mathrm{MHz}$ a. $\mathrm{u}^{-1}$, which was calculated by Bailey. ${ }^{22}$ This calculation yielded a nuclear coupling tensor with the diagonal elements $\chi_{a a}=1.9833 \mathrm{MHz}, \chi_{b b}=2.0254 \mathrm{MHz}$, and $\chi_{c c}=-4.0087 \mathrm{MHz}$, as well as the off diagonal elements $\chi_{a b}=-0.1255 \mathrm{MHz}, \chi_{a c}=-0.0001 \mathrm{MHz}$, and $\chi_{b c}=0.0016 \mathrm{MHz}$. The ${ }^{14} \mathrm{~N}$ nuclear quadrupole coupling constants (NQCCs) calculated with this method are in excellent agreement with the experimental values in many of our previous investigations on nitrogen containing molecules. ${ }^{9,10,23}$ 
BELGI-C1-hyperfine. As discussed in the introduction, we included the effect of weak nuclear quadrupole coupling in the $\mathrm{C}_{1}$ version of the BELGI program, ${ }^{4}$ and first tested this new version of our code on EAA, exhibiting $\mathrm{C}_{1}$ symmetry. ${ }^{9}$

To deal with the hfs, we used a perturbation approach similar to that used for acetamide, a $\mathrm{C}_{\mathrm{s}}$ molecule with one methyl internal rotor (see Eq. 1 of Ref. 24), but we extended it by including terms allowed under $\mathrm{C}_{1}$ symmetry. The procedure is the following: We first obtained the rotation-torsion eigenvalues and eigenvectors from the usual two-step diagonalization of the Hamiltonian $\mathrm{H}_{\mathrm{RT}}$ in the rho axis system. Our program was modified to output expectation values of $\left\langle P_{a}^{2}\right\rangle,\left\langle P_{b}^{2}\right\rangle,\left\langle P_{c}^{2}\right\rangle,\left\langle P_{a} P_{b}+P_{b} P_{a}\right\rangle,\left\langle P_{a} P_{c}+P_{c} P_{a}\right\rangle,\left\langle P_{b} P_{c}+P_{c} P_{b}\right\rangle$ in the rho axis system. We then put numerical values for these quantities into the standard hyperfine energy expression: $E_{h f}(I, J, F)=\left[\chi_{a a}\left\langle P_{a}^{2}\right\rangle+\chi_{b b}\left\langle P_{b}^{2}\right\rangle-\left(\chi_{a a}+\chi_{b b}\right)\left\langle P_{c}^{2}\right\rangle+\chi_{a b}\left\langle P_{a} P_{b}+P_{b} P_{a}\right\rangle+\chi_{a c}\left\langle P_{a} P_{c}+P_{c} P_{a}\right\rangle+\chi_{b c}\left\langle P_{b} P_{c}+\right.\right.$ $\left.\left.P_{c} P_{b}\right\rangle\right] 2 \frac{f(I, J, F)}{J(J+1)}$

where $f(I, J, F)$ is the Casimir function, ${ }^{25}$ which allowed us to calculate the shifts for each rotation-torsion energy level, and therefore to calculate the shifts $E_{h f^{\prime}}-E_{h f^{\prime \prime}}$ of hfs components for

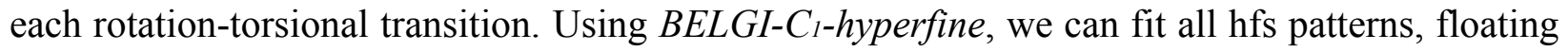
the nuclear quadrupole coupling constants together with the rotational and rotation-torsional parameters. The BELGI-Cl-hyperfine code can also be used to treat molecules with $\mathrm{C}_{\text {s }}$ symmetry like TBAA by fixing all out of plane $\mathrm{C}_{1}$ terms to zero.

\section{EXPERIMENTAL}

Measurements. TBAA, purchased from Alfa Aesar GmbH \& Co Kg, Karlsruhe, Germany, has a stated purity of $98 \%$ and was used without further purification. The substance was soaked on a pipe cleaner, used as carrier material, and placed upstream and very close the nozzle. Helium at a 
pressure of $150-200 \mathrm{kPa}$ was flown over the substance, and the helium-TBAA mixture was expanded into the vacuum chamber.

The spectra were recorded using a supersonic jet Fourier transform microwave spectrometer operating in the frequency range from 2 to $26.5 \mathrm{GHz} .{ }^{26}$ At first, a broadband scan from 9.0 to 12.8 GHz was carried out, where overlapping spectral segments were recorded in a step size of 0.25 MHz. All lines from the scans were remeasured in higher resolution with a measurement accuracy of about $2 \mathrm{kHz}$. They indicated a characteristic hfs due to the nuclear quadrupole coupling of the ${ }^{14} \mathrm{~N}$ nucleus. A portion of the broadband scan is shown in Figure 2, a typical measurement at high resolution in Figure 3.

Spectrum assignment. We often begin the spectrum assignment with a rigid rotor model, in which the effects of internal rotation and nuclear quadrupole coupling are neglected. However, from some previous investigations, especially those on $\mathrm{N}$-vinylformamide ${ }^{27}$ and $\mathrm{N}$ ethylacetamide, ${ }^{9}$ we know that the NQCCs can be calculated in almost exact agreement with the experimental values using the method given in section ${ }^{14} \mathrm{~N}$ nuclear quadrupole coupling constants. Therefore, in the case of TBAA, we took into account the effect of ${ }^{14} \mathrm{~N}$ quadrupole coupling directly at the beginning, and assigned the observed hfs by comparing it with the calculated hyperfine frequencies. Some A species $Q$-branch transitions with their characteristic hyperfine patterns could be readily identified and fitted. Afterwards, the number of assigned A species transitions was gradually increased to 26 (with 110 hyperfine components). As a next step, we removed all assigned A species from the broadband scan and used the same procedure as reported in Ref. 9 to assign the E species lines. Since we expected the barrier height in TBAA to be close to that found in EAA $\left(73.4782(1) \mathrm{cm}^{-1}\right)$, several XIAM predictions were performed, where we varied the barrier to internal rotation from 50 to $100 \mathrm{~cm}^{-1}$ with a step width of $5 \mathrm{~cm}^{-1}$. 
Good agreement between the calculated E species frequencies and the frequencies of the remaining lines in the scan was observed at $65 \mathrm{~cm}^{-1}$.

A global fit of TBAA including $26 \mathrm{~A}$ and $35 \mathrm{E}$ species transitions with a total of 250 hyperfine components was carried out with the program XIAM. The root-mean-square (rms) deviation is

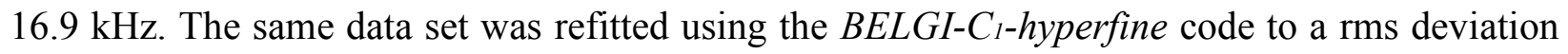
close to the measurement accuracy of $2 \mathrm{kHz}$. The fit results are given in Table 1, the frequency list is available in Table S-2 in the SI.

\section{FITS AND DISCUSSIONS}

Results of the fits. The microwave spectrum of the $\mathrm{C}_{\mathrm{s}}$ trans conformer of TBAA was assigned and fitted with the programs $X I A M$ and $B E L G I-C_{1}$-hyperfine. Using the program $X I A M$, we fitted the transitions frequencies to determine 14 parameters, which are three linear combinations of the rotational constants $B_{J}, B_{K}, B_{-}$, three quartic centrifugal distortion constants $D_{J}, D_{J K}$, and $d_{J}$, the NQCCs $\chi_{a a}, \chi_{b b}-\chi_{c c}$, and $\chi_{a b}$, as well as five internal rotation parameters (the barrier to internal rotation $V_{3}$, three higher order terms $D_{p i 2 J}, D_{p i 2 K}, D_{p i 2-}$, and the angle $\delta$ between the internal rotor axis and the principal $a$ axis). The results are given as Fit XIAM in Table 1.

Using the BELGI-C $C_{1}$-hyperfine code, 17 parameters were floated (with the rotational constant $F$ of the internal rotor fixed at the value from the XIAM fit), i.e. the NQCCs $\chi_{a a}, \chi_{b b}$, and $\chi_{a b}$ in Eq. (1), together with the three rotational constants $A, B, C$, four centrifugal distortion constants $\Delta J$, $\Delta_{K}, \delta_{\text {, }}$ and $\delta_{K}$, the $D_{a b}$ parameter (multiplying the off-diagonal $\left(P_{a} P_{b}+P_{b} P_{a}\right)$ terms), the potential barrier height $V_{3}$, the rotation-torsion coupling term $\rho$, and four higher order terms which represent the rotation-torsion interaction. All out-of-plane terms were set to zero due to the $\mathrm{C}_{\mathrm{s}}$ symmetry of TBAA. The internal rotation constant $F$ was fixed to the value determined with 
$X I A M$. The rms deviation of all 250 hyperfine components is $3.0 \mathrm{kHz}$, which is very close to the measurement accuracy. Parameters which can be transformed into the principal axis system are given as Fit BELGI in Table 1. The BELGI-Cl-hyperfine parameters in the rho axis system are summarized in Table 2.

The BELGI-Cl-hyperfine code also shows its efficiency for fitting the microwave spectrum of EAA. As reported in Ref. 9, four E species transitions $\left(2_{11} \leftarrow 1_{11}, 2_{12} \leftarrow 1_{01}, 3_{03} \leftarrow 2_{12}, 3_{13} \leftarrow 202\right)$ were excluded in a fit using the program XIAM because of their large observed-minus-calculated values (see the frequency list given in the SI of Ref. 9). Using the BELGI-Cl-hyperfine code, the same data set as in Ref. 9, but including these four transitions, were fitted to a rms deviation of $2.7 \mathrm{kHz}$, much better than that of the XIAM fit. In the BELGI fit of EAA we floated 20 parameters, which are also listed in Table 2. It should be noted that the out-of-plane $D_{a c i}$ and $D_{a c s i}$ parameters, which multiply the $P_{a} P_{c}+P_{c} P_{a}$ and $P^{2}\left(P_{a} P_{c}+P_{c} P_{a}\right)$ terms, respectively, are well determined, while the $D_{b c i}$ parameter (multiplying the $P_{b} P_{c}+P_{c} P_{b}$ terms) could not be fitted and was set to zero. All fitted transitions of EAA along with their residuals are available in Table S3; parameters transformed into the principal axis system in Table S-4.

Discussions. The rotational constants $A, B, C$ deduced from the XIAM and BELGI-CI-hyperfine fits are of high accuracy and in excellent agreement with the values calculated at the MP2/6$311++\mathrm{G}(\mathrm{d}, \mathrm{p})$ level of theory. The centrifugal distortion constants calculated using anharmonic frequency calculations are also close to the experimental values. The NQCCs determined in both fits are essentially the same, and are as expected very well calculated using the method given in section ${ }^{14} N$ nuclear quadrupole coupling constants.

The barrier to internal rotation of the acetyl methyl group in TBAA was fitted by the program XIAM to be $65.5668(1) \mathrm{cm}^{-1}$, which is close to the barrier of $64.91548(41) \mathrm{cm}^{-1}$ obtained with BELGI-Cl-hyperfine. In comparison to the values of $73.468(51) \mathrm{cm}^{-1}$ and $73.4782(1) \mathrm{cm}^{-1}$ found 
for $\mathrm{N}$-methylacetamide ${ }^{28}$ and EAA, ${ }^{9}$ respectively, the barrier in TBAA decreases by about 8 $\mathrm{cm}^{-1}$. This is strange, because we expect that the bulky tert-butyl group increases the acetyl methyl barrier height because of the sterical effect, as already observed in esters by comparing methyl acetate $\left(102.413(20) \mathrm{cm}^{-1}\right)^{29}$ and ethyl acetate $\left(101.606(23) \mathrm{cm}^{-1}\right)^{11}$ with tert-butyl acetate $\left(112.983(13) \mathrm{cm}^{-1}\right) \cdot{ }^{30}$ However, since electronic effects might have a much stronger influence on the barrier to internal rotation of the acetyl methyl group than the sterical hindrance, as discussed in Ref. 9, we suspect that sizable electronic effects occurring from the orientation of the tertbutyl group connected to the amide bond lead to the decrease of the potential barrier in TBAA. On the other hand, it is interesting that the barrier to internal rotation of the acetyl methyl group in TBAA is almost the same as those of two conformers of ethylacetamidoacetate (63.695(61) $\mathrm{cm}^{-1}$ and $\left.64.756(63) \mathrm{cm}^{-1}\right)^{31}$ and that of $64.96(4) \mathrm{cm}^{-1}$ found for $\mathrm{N}$-acetyl alanine methyl ester. ${ }^{32}$ Unfortunately, not like in the case of acetates, ${ }^{33}$ the limited number of data points is not sufficient to give any definitive statement on the acetyl internal rotation barrier in acetamides.

The $a b$ initio barrier height of $119 \mathrm{~cm}^{-1}$ was obtained by rotating the acetyl methyl group in a grid of $10^{\circ}$, and the structure was optimized except for the frozen dihedral angle $\gamma$ defining the torsional coordinate. The ab initio barrier is almost twice the experimental value. Many previous investigations have shown that calculating the potential barriers is a difficult task. The predicted values vary in a wide range and depend strongly on the level of theory in use. ${ }^{33,34}$ Considering the zero point energy correction might improve the results. ${ }^{31}$ Nevertheless, it requires frequency calculations for the transition states, which cannot be performed at high level of theory due to the limitation of our computational resources. Furthermore, a level that yields reasonable value for a methyl group may fail for another methyl group, even in the same molecule (for example see Table VII in Ref. 31). High level quantum chemical methods such as diffusion quantum Monte 
Carlo and coupled cluster are not forcedly in best agreement with the experiments. ${ }^{10}$ Currently, no general methods exist to calculate the methyl barrier height. However, results from quantum chemical calculations often give the correct order of magnitude (low, intermediate, or high) of the barrier heights, which is sufficient to hint the authors in the spectral assignment step.

It is worth noting that almost all lines observed in the broadband scan could be assigned to the trans conformer of TBAA. The trans conformer is thus the only conformer, which can be observed under our measurement conditions.

\section{CONCLUSION}

The microwave spectrum of N-tert-butylacetamide was measured between 2 and $26.5 \mathrm{GHz}$ using a molecular beam Fourier transform microwave spectrometer with a measurement accuracy of 2 $\mathrm{kHz}$. Only one conformer with trans configuration and $\mathrm{C}_{\mathrm{s}}$ symmetry was observed in the spectrum. The data set was fitted using the programs XIAM and BELGI-C -hyperfine to rms deviations of $16.9 \mathrm{kHz}$ and $3.0 \mathrm{kHz}$, respectively. Both XIAM and BELGI fits included $26 \mathrm{~A}$ and 35 E species transitions with a total of $250 \mathrm{hfs}$ components, determining 14 and 17 molecular parameters, respectively. All comparable fitted parameters were in excellent agreement. The barrier to internal rotation of the acetyl methyl group was approximately $65 \mathrm{~cm}^{-1}$, surprisingly lower than that of about $73 \mathrm{~cm}^{-1}$ found in N-methylacetamide and N-ethylacetamide, but close to that found in ethylacetamidoacetate and $\mathrm{N}$-acetyl alanine methyl ester. The BELGI-C -hyperfine $^{-}$ code was also used to refit the microwave spectrum of N-ethylacetamide reported in Ref. 9 to measurement accuracy. 


\section{ASSOCIATED CONTENT}

Supporting Information. Cartesian coordinates of the trans and cis conformers, lists of fitted frequencies along with their residuals of trans $\mathrm{N}$-tert-butylacetamide and N-ethylacetamide, BELGI-C $C_{1}$-hyperfine parameters in the principal axis system of $\mathrm{N}$-ethylacetamide. This material is available free of charge via the Internet at http://pubs.acs.org.

\section{AUTHOR INFORMATION}

\section{Corresponding Author}

*Tel: +33 1451765 48. E-mail: lam.nguyen@lisa.u-pec.fr

\section{ACKNOWLEDGMENT}

We thank the Land Nordrhein-Westfalen for funds and the IT Center of the RWTH Aachen University for free computer time. R. K. thanks the graduate fond of the RWTH Aachen University for a Ph.D. fellowship. 


\section{REFERENCES}

(1) Woods, R.C. A General Program for the Calculation of Internal Rotation Splittings in Microwave Spectroscopy: Part II. The n-Top Problem. J. Mol. Spectrosc. 1967, 22, 4959.

(2) Hartwig, H.; Dreizler, H. The Microwave Spectrum of trans-2,3-Dimethyloxirane in Torsional Excited States. Z. Naturforsch. 1996, 51a, 923-932.

(3) Hougen, J. T.; Kleiner, I.; Godefroid, M. Selection Rules and Intensity Calculations for a Cs Asymmetric Top Molecule Containing a Methyl Group Internal Rotor. J. Mol. Spectrosc. 1994, 163, 559-586.

(4) Kleiner, I.; Hougen, J. T. Rho-Axis-Method Hamiltonian for Molecules Having one Methyl Rotor and $\mathrm{C}_{1}$ Point-group Symmetry at Equilibrium. J. Chem. Phys. 2003, 119, 5505-5509.

(5) Groner, P. Effective Rotational Hamiltonian for Molecules with Two Periodic LargeAmplitude Motions. J. Chem. Phys. 1997, 107, 4483-4498.

(6) Ilyushin, V. V.; Kisiel, Z.; Pszczół kowski, L.; Mäder, H.; Hougen, J. T. A New TorsionRotation Fitting Program for Molecules with a Six-Fold Barrier: Application to the Microwave Spectrum of Toluene. J. Mol. Spectrosc. 2010, 259, 26-38.

(7) Private communication with Dr. V. V. Ilyushin.

(8) Fliege, E.; Dreizler, H.; Demaison, J.; Boucher, D.; Burie, J., Dubrulle, A. Centrifugal Distortion and Internal Rotation Analysis of the Microwave Spectrum of Ethyl Fluoride. J. Chem. Phys. 1983, 78, 3541. 
(9) Kannengießer, R.; Lach, M. J.; Stahl, W.; Nguyen, H. V. L. Acetyl Methyl Torsion in NEthylacetamide: A Challenge for Microwave Spectroscopy and Quantum Chemistry. ChemPhysChem. 2015, 16, 1906-1911.

(10) Kannengießer, R.; Klahm, S.; Nguyen, H. V. L.; Lüchow, A.; Stahl, W. The Effects of Methyl Internal Rotation and ${ }^{14} \mathrm{~N}$ Quadrupole Coupling in the Microwave Spectra of Two Conformers of N,N-diethylacetamide. J. Chem. Phys. 2014, 141, 204308.

(11) Jelisavac, D.; Cortés-Gómez, D. C., Nguyen, H. V. L.; Sutikdja, L. W.; Stahl, W.; Kleiner, I. The Microwave Spectrum of the trans Conformer of Ethyl Acetate. J. Mol. Spectrosc. 2009, 257, 111-115.

(12) Nguyen, H. V. L.; Jabri, A.; Van, V.; Stahl, W. Methyl Internal Rotation in the Microwave Spectrum of Vinyl Acetate. J. Phys. Chem. A 2014, 118, 12130-12136.

(13) Zhao, Y.; Jin, J.; Stahl, W.; Kleiner, I. The Microwave Spectrum of Methyl Neopentyl Ketone. J. Mol. Spectrosc. 2012, 281, 4-8.

(14) Nguyen, H. V. L.; Mouhib, H.; Stahl W.; Kleiner I. The Microwave Spectrum of Allyl Acetate. Mol. Phys. 2010, 108, 763-770.

(15) Nguyen, H. V. L.; Mouhib, H.; Klahm, S.; Stahl W.; Kleiner I. A touch of lavender: gasphase structure and dynamics of the monoterpene linalool validated by microwave spectroscopy. Phys. Chem. Chem. Phys. 2013, 15, 10012-10018.

(16) Sutikdja, L. W.; Jelisavac, D.; Stahl, W.; Kleiner, I. Structural Studies on Banana Oil, Isoamyl Acetate, by Means of Microwave Spectroscopy and Quantum Chemical Calculations. Mol. Phys. 2012, 110, 2883-2893. 
(17) Tulimat, L.; Mouhib, H.; Kleiner I.; Stahl W. The microwave spectrum of allyl acetone. J. Mol. Spectrosc. 2015, 312, 46-50.

(18) Attig, T.; Sutikdja, L. W.; Kannengießer, R.; Kleiner, I.; Stahl, W. The Microwave Spectrum of n-Butyl Acetate. J. Mol. Spectrosc. 2013, 284-285, 8-15.

(19) Attig, T.; Kannengießer, R.; Kleiner, I.; Stahl, W. Conformational Analysis of n-Pentyl Acetate Using Microwave Spectroscopy. J. Mol. Spectrosc. 2013, 290, 24-30.

(20) Attig, T.; Kannengießer, R.; Kleiner, I.; Stahl, W. The Microwave Spectrum of n-Hexyl Acetate and Structural Aspects of n-Alkyl Acetates. J. Mol. Spectrosc. 2014, 298, 47-53.

(21) Frisch, M. J.; Trucks, G. W.; Schlegel, H. B.; Scuseria, G. E.; Robb, M. A.; Cheeseman, J. R.; Scalmani, G.; Barone, V.; Mennucci, B.; Petersson, G. A. et al. Gaussian 09, Revision A.02, Gaussian, Inc.; Wallingford CT, 2009.

(22) Bailey, W. C. DFT and HF-DFT Calculations of ${ }^{14} \mathrm{~N}$ Quadrupole Coupling Constants in Molecules. Chem. Phys. 2000, 252, 57-66.

(23) Nguyen, H. V. L.; Kannengießer, R.; Stahl, W. Microwave Survey of the Conformational Landscape Exhibited by the Propeller Molecule Triethyl Amine. Phys. Chem. Chem. Phys. 2012, 14, 11753-11758.

(24) Suenram, R. D.; Golubiatnikov, G. Y.; Leonov, I. I.; Hougen, J. T.; Ortigoso, J.; Kleiner, I.; Fraser, G. T. Reinvestigation of the microwave spectrum of acetamide. J. Mol. Spectrosc. 2001, 208, 188-193.

(25) Townes, C. H.; Schawlow, A. L. Microwave Spectroscopy, McGraw-Hill, New York, 1955. 
(26) Grabow, J.-U.; Stahl, W.; Dreizler, H. A Pulsed Molecular Beam Microwave Fourier Transform Spectrometer with Parallel Molecular Beam and Resonator Axes. Z. Naturforsch. 1990, 45a, 1043-1044.

(27) Kannengießer, R.; Stahl, W.; Nguyen, H. V. L.; Bailey W. C. ${ }^{14}$ N Quadrupole Coupling in the Microwave Spectra of N-vinylformamide. J. Mol. Spectrosc. 2015, 317, 50-53.

(28) Ohashi, N.; Hougen, J. T.; Suenram, R. D.; Lovas, F. J.; Kawashima, Y.; Fujitake, M.; Pykad, J. Analysis and Fit of the Fourier-Transform Microwave Spectrum of the Two-top Molecule N-methylacetamide. J. Mol. Spectrosc. 2004, 227, 28-42

(29) Nguyen, H. V. L.; Kleiner I.; Shipman, S. T.; Mae, Y.; Hirose, K.; Hatanaka, S.; Kobayashi, K. Extension of the Measurement, Assignment, and Fit of the Rotational Spectrum of the Two-Top Molecule Methyl Acetate. J. Mol. Spectrosc. 2014, 299, $17-21$.

(30) Zhao, Y.; Li, G.; Mouhib, H.; Stahl, W.; Kleiner, I. Conformational Analysis of tertButyl Acetate Using a Combination of Microwave Spectroscopy and Quantum Chemical Calculations. J. Mol. Spectrosc. 2016, 322, 38-42.

(31) Plusquellic, D. F.; Kleiner, I; Demaison, J.; Suenram, R. D.; Lavrich, R. J. ; Lovas, F. J. ; Fraser, G. T. ; Ilyushin, V. V. The Microwave Spectrum of a Two-top Peptide Mimetic: The N-acetyl Alanine Methyl Ester Molecule. J. Chem. Phys. 2006, 125, 104312.

(32) Lavrich, R. J.; Hight Walker, A. R.; Plusquellic, D. F.; Kleiner, I.; Suenram, R. D.; Hougen, J. T.; Fraser, G. T. Conformational Analysis of the Jet-cooled Peptide Mimetic 
Ethylacetamidoacetate from Torsion-rotation Spectra. J. Chem. Phys. 2003, 119, 5497-5504.

(33) Jabri, A.; Van, V.; Nguyen, H. V. L.; Stahl, W.; Kleiner, I. Probing the Methyl Torsional Barriers of the $E$ and $Z$ Isomers of Butadienyl Acetate by Microwave Spectroscopy. ChemPhysChem. 2016, DOI: 10.1002/cphc.201600265.

(34) Van, V.; Stahl, W.; Nguyen, H. V. L. Two Equivalent Methyl Internal Rotations in 2,5Dimethylthiophene Investigated by Microwave Spectroscopy. Phys. Chem. Chem. Phys. 2015, 17, 32111-4. 


\section{FIGURES}

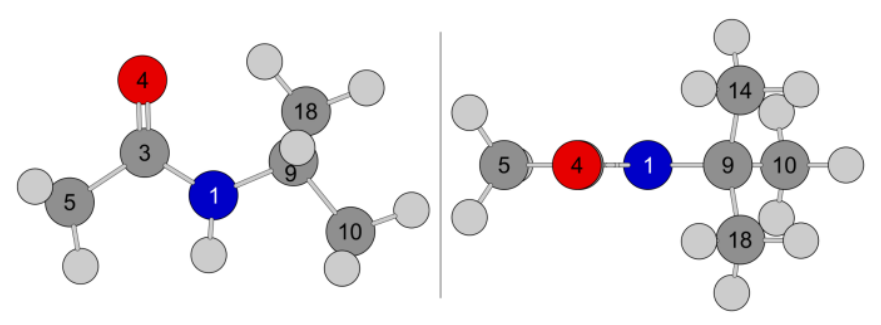

Figure 1. Optimized geometry of the trans conformer of N-tert-butylacetamide calculated at the MP2/6-311++G(d,p) level of theory. Right hand side: view along the $\mathrm{O}_{4}-\mathrm{C}_{3}$ bond, left hand side: front view.

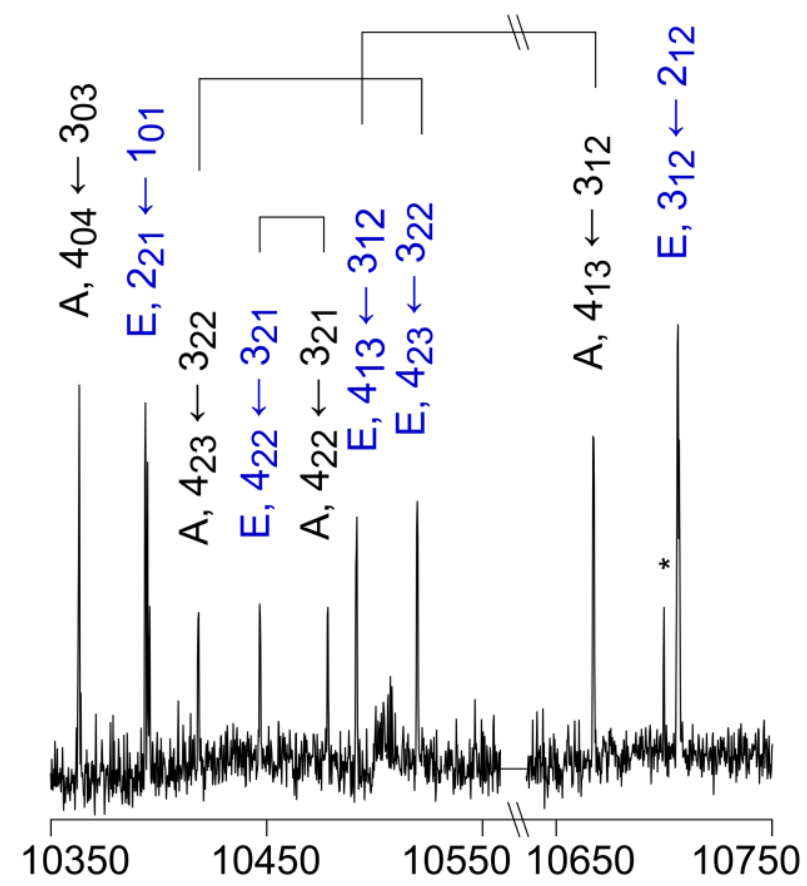

Figure 2. A portion of the broadband scan of N-tert-butylacetamide in the frequency range from 10350 to $10750 \mathrm{MHz}$. The transitions are marked with their respective quantum numbers and LAM symmetry species; the asterisk marks an unassigned line. A-E splittings are indicated by brackets. Additional splittings arise from the quadrupole coupling of the ${ }^{14} \mathrm{~N}$ nucleus. 


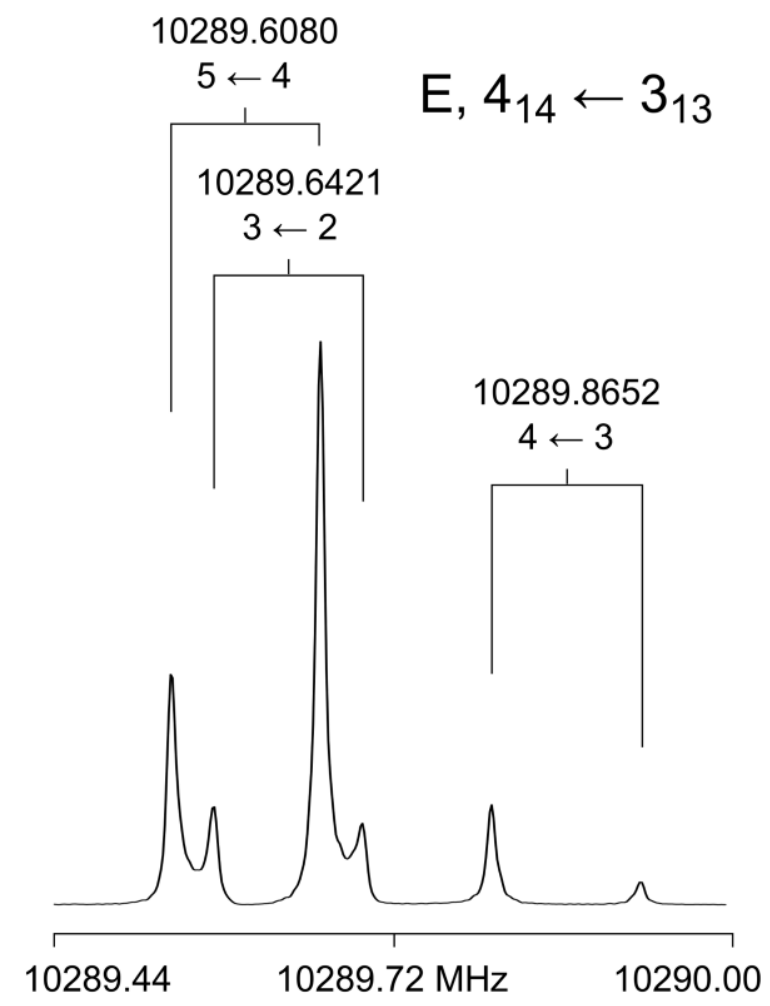

Figure 3. A high resolution spectrum of the $4_{14} \leftrightarrow 313$ E species transition of N-tertbutylacetamide. The Doppler doublets are marked by brackets. Hyperfine transitions are given by the respective F' $\mathrm{F}$ quantum numbers. For this spectrum, 380 decays were co-added. 


\section{TABLES}

Table 1. Molecular parameters of the observed trans conformer of N-tert-butylacetamide in the

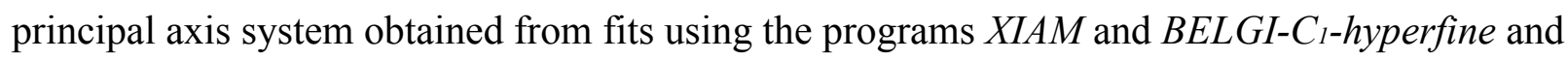
from quantum chemical calculations.

\begin{tabular}{|c|c|c|c|c|}
\hline Parameter $^{\mathrm{a}}$ & Unit & Fit $X I A M^{b}$ & Fit $B E L G I^{\mathrm{c}}$ & Calc. $^{d}$ \\
\hline$A$ & $\mathrm{MHz}$ & $3302.4457(46)$ & $3304.8012(16)$ & 3307.1 \\
\hline$B$ & $\mathrm{MHz}$ & $1365.5902(17)$ & $1364.2402(14)$ & 1365.5 \\
\hline$C$ & $\mathrm{MHz}$ & $1238.8312(14)$ & $1238.48089(62)$ & 1237.8 \\
\hline$D_{J}$ & $\mathrm{kHz}$ & $0.1042(81)$ & $0.1016(20)$ & 0.0872 \\
\hline$D_{J K}$ & $\mathrm{kHz}$ & $0.529(80)$ & & 0.4594 \\
\hline$d_{1}$ & $\mathrm{kHz}$ & $-0.0169(66)$ & & -0.0055 \\
\hline$\chi_{a a}$ & $\mathrm{MHz}$ & $2.0129(72)$ & $2.0118(35)$ & $1.9833^{\mathrm{e}}$ \\
\hline$\chi_{b b}-\chi_{c c}$ & $\mathrm{MHz}$ & $5.827(18)$ & $5.8278(58)$ & $6.0342^{\mathrm{e}}$ \\
\hline$\chi_{a b}$ & $\mathrm{MHz}$ & $-0.144(28)$ & $-0.1395(37)$ & $-0.1255^{\mathrm{e}}$ \\
\hline$V_{3}$ & $\mathrm{~cm}^{-1}$ & $65.5668(1)$ & $64.91548(41)$ & 119. \\
\hline$F_{0}$ & $\mathrm{GHz}$ & $158.0^{f}$ & $158.062356(27)$ & \\
\hline$D_{p i 2 J}$ & $\mathrm{kHz}$ & $-52.27(17)$ & & \\
\hline$D_{p i 2 K}$ & $\mathrm{kHz}$ & $529.1(12)$ & & \\
\hline$D_{p i 2-}$ & $\mathrm{kHz}$ & $-28.01(35)$ & & \\
\hline$\angle(i, a)$ & deg & $32.4448(1)$ & $32.56356(15)$ & 34.95 \\
\hline$\angle(i, b)$ & deg & $57.5552(1)$ & $57.43644(15)$ & 55.05 \\
\hline$\angle(i, c)$ & deg & $90.0^{\mathrm{f}}$ & $90.0^{\mathrm{f}}$ & 90.00 \\
\hline $\mathrm{rms}^{\mathrm{g}}$ & $\mathrm{kHz}$ & 16.9 & 3.0 & \\
\hline $\mathrm{N}_{\mathrm{A}} / \mathrm{N}_{\mathrm{E}} / \mathrm{N}_{\mathrm{q}}{ }^{\mathrm{h}}$ & & $110 / 140 / 250$ & $110 / 140 / 250$ & \\
\hline
\end{tabular}

a All parameters refer to the principal axis system. Statistical uncertainties are given as one standard uncertainty in the last digit. ${ }^{\mathrm{b}}$ Watson's S reduction and $\mathrm{I}^{\mathrm{r}}$ representation were used, with $\mathrm{d}_{2}$ set to zero. ${ }^{\mathrm{c}}$ Obtained by transformation from the rho axis system to the principal axis system (for details see Ref. 11). ${ }^{\mathrm{d}}$ Calculated at the MP2/6-311++G(d,p) level of theory. ${ }^{\mathrm{e}}$ Electric field gradient single point calculation at the B3PW91/6-311+(df,pd) level of theory. ${ }^{\mathrm{f}}$ Fixed value. ${ }^{\mathrm{g}}$ Root-mean-square deviation of the fit. ${ }^{\mathrm{h}}$ Number of $\mathrm{A}$ and $\mathrm{E}$ species transitions as well as hyperfine components, respectively. 
Table 2. Spectroscopic constants of $\mathrm{N}$-tert-butylacetamide ( $\mathrm{C}_{\text {s }}$ symmetry) and $\mathrm{N}$-ethylacetamide

$\left(\mathrm{C}_{1}\right.$ symmetry $)$ in the rho axis system obtained with the program BELGI-Cl-hyperfine.

\begin{tabular}{|c|c|c|c|c|}
\hline Parameter $^{\mathrm{a}}$ & Unit & TBAA & EAA & Operator \\
\hline$A$ & $\mathrm{MHz}$ & $3178.6949(12)$ & $7158.6153(12)$ & $\mathrm{Pa}^{2}$ \\
\hline$B$ & $\mathrm{MHz}$ & $1490.34657(62)$ & $2277.9833(32)$ & $\mathrm{Pb}_{\mathrm{b}}{ }^{2}$ \\
\hline C & $\mathrm{MHz}$ & $1238.48091(62)$ & $1961.4748(10)$ & $\mathrm{P}_{\mathrm{c}}{ }^{2}$ \\
\hline$D_{a b}$ & $\mathrm{MHz}$ & $478.3453(24)$ & 715.186(18) & $\left\{\mathrm{P}_{\mathrm{a}}, \mathrm{P}_{\mathrm{b}}\right\}$ \\
\hline$D_{a c i}$ & $\mathrm{MHz}$ & $0.0^{\mathrm{b}}$ & $-291.1414(50)$ & $\left\{\mathrm{P}_{\mathrm{a}}, \mathrm{P}_{\mathrm{c}}\right\}$ \\
\hline$D_{a c c_{i}}$ & $\mathrm{kHz}$ & $0.0^{\mathrm{b}}$ & $2.611(85)$ & $\mathrm{P}^{2}\left\{\mathrm{P}_{\mathrm{a}}, \mathrm{P}_{c}\right\}$ \\
\hline$\Delta$ & $\mathrm{kHz}$ & $0.1016(20)$ & $1.2533(45)$ & $-\mathrm{P}^{4}$ \\
\hline$\Delta_{J K}$ & $\mathrm{kHz}$ & $0.0^{\mathrm{c}}$ & $-0.885(21)$ & $-\mathrm{P}^{2} \mathrm{P}_{\mathrm{a}}^{2}$ \\
\hline$\Delta K$ & $\mathrm{kHz}$ & $2.00(13)$ & $17.23(19)$ & $-\mathrm{Pa}^{4}$ \\
\hline$\delta_{J}$ & $\mathrm{kHz}$ & $0.0254(21)$ & $0.0724(42)$ & $-2 \mathrm{P}^{2}\left(\mathrm{P}^{2}-\mathrm{Pc}^{2}\right)$ \\
\hline$\delta_{K}$ & $\mathrm{kHz}$ & $-0.468(59)$ & $-7.136(69)$ & $-\left\{\mathrm{Pa}^{2},\left(\mathrm{P}_{\mathrm{b}}^{2}-\mathrm{P}_{\mathrm{c}}^{2}\right)\right\}$ \\
\hline$\chi_{a a}$ & $\mathrm{MHz}$ & $4.1477(60)$ & $3.8943(62)$ & \\
\hline$\chi_{b b}$ & $\mathrm{MHz}$ & $3.6919(67)$ & $3.6666(62)$ & \\
\hline$\chi_{c c}$ & $\mathrm{MHz}$ & $-7.8396^{\mathrm{d}}$ & $-7.5609^{d}$ & \\
\hline$\chi_{a b}$ & $\mathrm{MHz}$ & $-0.1916(80)$ & $-1.257(19)$ & \\
\hline$V_{3}$ & $\mathrm{~cm}^{-1}$ & $64.91548(41)$ & $73.08159(26)$ & $(1 / 2)(1-\cos 3 \gamma)$ \\
\hline$\rho$ & unitless & $0.01795553(18)$ & $0.04082824(25)$ & $\mathrm{P}_{\mathrm{a}} \mathrm{P}_{\gamma}$ \\
\hline$F$ & $\mathrm{~cm}^{-1}$ & $5.3641^{\mathrm{e}}$ & $5.4845^{\mathrm{e}}$ & $\mathrm{P}_{\gamma}^{2}$ \\
\hline$d_{a b}$ & $\mathrm{MHz}$ & $-3.6271(58)$ & $-7.383(48)$ & $(1-\cos 3 \gamma)\left\{\mathrm{P}_{\mathrm{a}}, \mathrm{P}_{\mathrm{b}}\right\}$ \\
\hline$k_{1}$ & $\mathrm{MHz}$ & $0.0^{\mathrm{c}}$ & $0.1512(25)$ & $\left(\mathrm{P}_{\mathrm{a}} \mathrm{P}_{\gamma}\right) \mathrm{P}_{\mathrm{a}}^{2}$ \\
\hline$c_{1}$ & $\mathrm{MHz}$ & $0.0^{\mathrm{c}}$ & $-0.01642(30)$ & $\mathrm{P}_{\gamma}^{2}\left(\mathrm{P}_{\mathrm{b}}^{2}-\mathrm{P}_{\mathrm{c}}^{2}\right)$ \\
\hline$c_{4}$ & $\mathrm{MHz}$ & $-0.00140(24)$ & $0.0^{\mathrm{c}}$ & $(1-\cos 3 \gamma) \mathrm{P}_{\mathrm{a}}^{2}$ \\
\hline$F_{v}$ & $\mathrm{MHz}$ & $0.5748(15)$ & $0.0^{\mathrm{c}}$ & $(1-\cos 3 \gamma) \mathrm{P}^{2}$ \\
\hline$G_{v}$ & $\mathrm{MHz}$ & $0.0^{\mathrm{c}}$ & $-0.02219(55)$ & $\mathrm{P}_{\gamma}^{2} \mathrm{P}^{2}$ \\
\hline$L_{v}$ & $\mathrm{MHz}$ & $0.00233(12)$ & $0.0^{\mathrm{c}}$ & $\left(\mathrm{P}_{a} \mathrm{P}_{\gamma}\right) \mathrm{P}^{2}$ \\
\hline $\mathrm{N}_{\mathrm{A}} / \mathrm{N}_{\mathrm{E}} / \mathrm{N}_{\mathrm{q}}^{\mathrm{f}}$ & & $110 / 140 / 250$ & $150 / 125 / 275$ & \\
\hline $\mathrm{rms} \mathrm{A} / \mathrm{E}^{\mathrm{g}}$ & $\mathrm{kHz}$ & $2.5 / 3.3$ & $1.7 / 3.5$ & \\
\hline
\end{tabular}

${ }^{a}$ All parameters refer to the rho-axis system and cannot be directly compared to those referred to the principal axis system. $\mathrm{P}_{\mathrm{a}}, \mathrm{P}_{\mathrm{b}}$, and $\mathrm{P}_{\mathrm{c}}$ are the components of the overall rotation angular momentum, $\mathrm{P}_{\gamma}$ is the angular momentum of the internal rotor rotating about the internal rotor axis by an angle $\gamma .\{\mathrm{u}, \mathrm{v}\}$ is the anti-commutator $\mathrm{uv}+\mathrm{vu}$. The product of the parameter and 
operator from a given row yields the term actually used in the vibration-rotation-torsion Hamiltonian, except for $F, \rho$, and $A$, which occur in the Hamiltonian in the form $F\left(\mathrm{P}_{\gamma}-\rho \mathrm{P}_{a}\right)^{2}+$ $A \mathrm{P}_{\mathrm{a}}{ }^{2}$. Statistical uncertainties are shown as one standard uncertainty in the last digit. ${ }^{\mathrm{b}}$ These parameters are not allowed for a $\mathrm{C}_{\mathrm{s}}$ symmetry molecule, and therefore are set to zero. ${ }^{\mathrm{c}}$ Not fitted parameters, set to zero. ${ }^{\mathrm{d}}$ Derived from the linear combination $\chi_{c c}=-\left(\chi_{a a}+\chi_{b b}\right) .{ }^{\mathrm{e}}$ Fixed to the value from a XIAM fit. ${ }^{\mathrm{f}}$ Number of $\mathrm{A}$ and $\mathrm{E}$ species transitions as well as hyperfine components. ${ }^{\mathrm{g}}$ Root-mean-square deviations of the $\mathrm{A}$ and $\mathrm{E}$ species.

\section{Graphical abstract:}

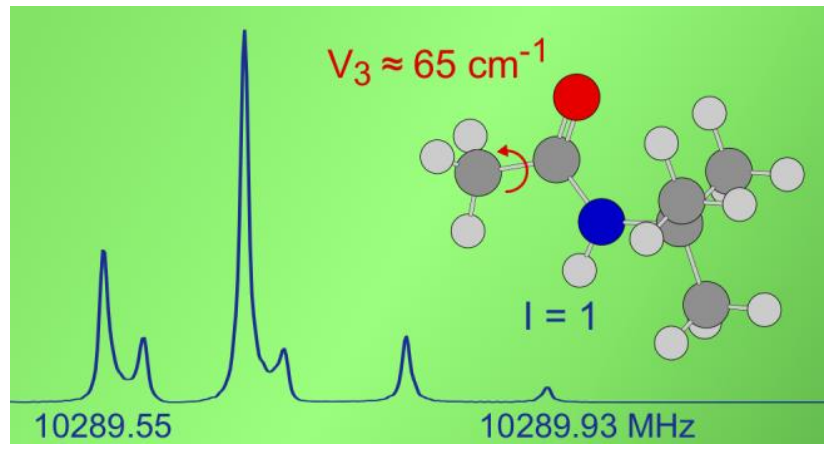

